\title{
EMATER/RS - ASCAR: Estudo de caso sobre o assistente social na política de ATER
}

\author{
Radünz, Amanda Fabres Oliveira ${ }^{1,4}$; Zuleika da Silva Gonçalves ${ }^{2}$; André Luiz Radunz ${ }^{3}$ \\ ${ }^{1}$ Empresa Brasileira de Serviços Hospitalares - EBSERH/UFPel; ${ }^{2}$ Universidade Católica Dom Bosco (UCDB); \\ ${ }^{3}$ Universidade Federal da Fronteira Sul, UFFS, Campus Chapecó, Curso de agronomia, Chapecó, SC, Brasil; \\ 4amafaol@yahoo.com.br
}

Radünz, Amanda Fabres Oliveira; Zuleika da Silva Gonçalves; André Luiz Radunz (2019) EMATER/RS ASCAR: Estudo de caso sobre o assistente social na política de ATER. Rev. Fac. Agron. Vol 118 (1): 123131.

A assistência técnica e extensão rural (ATER) esta pautada na construção coletiva do conhecimento e na valorização do saber para a redução das desigualdades, preocupando-se com as condições e qualidade de vida da população rural e o pleno exercício da cidadania. No Rio Grande do Sul a Associação Rio-Grandense de Empreendimentos de Assistência Técnica e Extensão Rural (EMATER/RS - ASCAR) é responsável pelo desenvolvimento de ações de ATER. Para tanto, conta com uma equipe multidisciplinar, da qual faz parte o assistente social. Com base no exposto, objetivou-se compreender a dinâmica de trabalho dos assistentes sociais lotados na EMATER/RS e como a instituição está organizada no tocante ao trabalho com a questão social e suas expressões. Desta maneira, delimitou-se o campo de pesquisa aos profissionais assistentes sociais lotados na EMATER/RS, sendo os dados coletados a partir de um estudo qualitativo, através de entrevista estruturada - composta por perguntas abertas - e pesquisa bibliográfica. Os resultados demonstraram que 0 número de assistentes sociais vinculadas à EMATER/RS é de apenas duas profissionais, sendo este número insuficiente para atender as demandas de todo o estado. Todavia, esses resultados também apontaram que o assistente social tem sido cada vez mais reconhecido pelo público atendido e demais agentes de ATER.

Palavras-chave: Assistência técnica; extensão rural; Serviço social; ATER

Radünz, Amanda Fabres Oliveira; Zuleika da Silva Gonçalves; André Luiz Radunz (2019) EMATER / RS ASCAR: Case study on the social assistant in ATER policy. Rev. Fac. Agron. Vol 118 (1): 123-131.

\begin{abstract}
Technical assistance and rural extension (ATER) is based on the collective construction of knowledge and the valorisation of knowledge for the reduction of inequalities, being concerned with the conditions and quality of life of the rural population and the full exercise of citizenship. In Rio Grande do Sul, the Rio-Grandense Association of Enterprises for Technical Assistance and Rural Extension (EMATER / RS - ASCAR) is responsible for the development of ATER actions. For such, it counts on a multidisciplinary team, of which the social worker is part. Based on the above, the objective was to understand the work dynamics of the social workers crowded in EMATER / RS and how the institution is organized in relation to work with the social question and its expressions. In this way, the field of research was delimited to the social assistants crowded at EMATER / RS, and the data were collected from a qualitative study, through a structured interview - composed of open questions - and bibliographic research. number of social workers linked to EMATER / RS is only two professionals, and this number is insufficient to meet the demands of the entire state. However, these results also pointed out that the social worker has been increasingly recognized by the attending public and other ATER agents.
\end{abstract}

Keywords: Technical assistance; rural extension; Professional participation; Social servisse; ATER

\author{
https://doi.org/10.24215/16699513e012 \\ https://revistas.unlp.edu.ar/revagro \\ Recibido: 20/09/2017 \\ Aceptado: 28/05/2018 \\ Disponible on line: $01 / 07 / 2019$
}

ISSN 0041-8676 - ISSN (on line) 1669-9513, Facultad de Ciencias Agrarias y Forestales, UNLP, Argentina 


\section{INTRODUÇÃO}

A assistência técnica e extensão rural (ATER), segundo a proposição da nova Política Nacional de Assistência Técnica e Extensão Rural (PNATER), têm em sua essência a promoção e circulação de processos que venham a contribuir para estratégias de desenvolvimento rural sustentável (Brasil, 2010, p. 3). Contexto este em que a assistência tecnológica agrícola deixa de ser foco exclusivo e preponderante nas atividades de extensão rural e passa a se desafiar considerando a complexidade da realidade do campo.

A atuação do assistente social insere-se neste processo de extensão rural, com ações voltadas aos processos de sustentabilidade da Agricultura Familiar e de defesa e garantia de direitos da população rural. Sendo assim, exerce o papel de agente mediador de ações que convergem para a efetivação de direitos dos agricultores e que possibilitem a melhoria da qualidade de vida de suas famílias (Santos, 2010). A participação dos atores sociais nas discussões que lhes dizem respeito e nos mais diversos âmbitos da vida social é estimulada através de iniciativas de controle social, o qual auxilia no desenvolvimento de políticas, na tomada de decisão e, por conseguinte, nos processos democráticos e cidadãos.

Com base no exposto, este trabalho aborda o desenvolvimento da política de assistência técnica e extensão rural (ATER), tendo como enfoque a atuação do assistente social. Para tanto, delimitou-se o campo de pesquisa aos profissionais assistentes sociais lotados na Associação Rio-Grandense de Empreendimentos de Assistência Técnica e Extensão Rural (EMATER/RS - ASCAR). O objetivo deste trabalho foi, portanto, compreender a dinâmica de trabalho dos assistentes sociais lotados na EMATER/RS e como a instituição está organizada no tocante ao trabalho com a questão social e suas expressões. Trata-se de um estudo qualitativo, o qual baseou-se nas respostas obtidas através de entrevista estruturada - com o auxílio de um roteiro previamente organizado com perguntas abertas - e pesquisa bibliográfica. O tamanho da amostra foi definido, muito em função do conjunto de assistentes sociais que atuam na instituição e no cargo referido (sabe-se que há outros indivíduos com formação em Serviço Social, porém exercendo suas funções em outros cargos).

O tema ora abordado é de suma relevância acadêmica e social, pois é na seara das discussões sobre a agricultura familiar e o meio rural ainda pouco debatido. Conforme pode-se observar no decorrer deste artigo, são parcos os estudos elaborados com a finalidade de identificar/conhecer a ação do profissional de Serviço Social em agências e/ou instituições de extensão rural.

Em estudos anteriores por nós realizados observamos que embora haja uma presença significativa de Assistentes Sociais inseridos nas instituições que operacionalizam ações e políticas de reforma agrária, as reflexões e sistematizações dos pesquisadores de Serviço Social não têm acompanhado esse movimento da realidade. Afirmamos isto tendo em vista a pouca expressão dos estudos, pesquisas, artigos e sistematizações acerca da inserção do assistente social na questão agrária e nas políticas de reforma agrária (Silva, 2017, p. 1).
Embora nos últimos anos tenha-se identificado a presença dos assistentes sociais em organizações e instituições de ATER, este tema como objeto de estudo é a priori preterido quando comparado a outros. Portanto, ao desenvolver este estudo há um esforço em destacar a ação profissional, nesta área que é por excelência ocupada preponderantemente por profissionais das ciências agrárias, contribuindo - ainda que de maneira acanhada - no debate sobre os espaços de atuação dos assistentes sociais e sua inserção num campo do conhecimento - no sentido bourdiesiano. Ademais, cabe frisar que para além desta categoria, outras serão utilizadas com finalidade teórica para compreensão da realidade. Com base na teoria de Pierre Bourdieu (2000), este estudo atenta para questões como as relações de poder e os capitais disponibilizados pelos agentes. Ademais, no concernente aos capitais acionados pelos agentes que atuam no campo ora estudado, cabe frisar não se tratar de capital monetário/financeiro. O capital referido aqui diz respeito aqueles abordados por Bourdieu (2000), principalmente os capitais escolar e simbólico.

Assim, o presente artigo está organizado em três seções. Na primeira seção - A Assistência Técnica e Extensão Rural - ATER no Brasil, elaborou-se um breve recorrido histórico sobre a política de ATER brasileira. Na sequência, discorreu-se a respeito da EMATER no Rio Grande do Sul, apontando como este instituição está organizada e a relevância de sua existência para o ATER no RS. A última parte: Serviço Social e a Extensão Rural no Brasil trata-se da participação dos Assistentes Sociais como agentes de ATER, as contribuições e limites da atuação de tais profissionais, bem como aborda a conjuntura laboral destes na EMATER/RS.

\section{A ASSISTÊNCIA TECNICA E EXTENSÃO RURAL- ATER NO BRASIL}

As primeiras iniciativas de extensão rural no Brasil remontam, de acordo com Peixoto (2008), a meados do século XIX, quando o governo federal inaugura institutos de pesquisa e de ensino agropecuário. A principal ação destes era o desenvolvimento e organização de estudos, os quais eram posteriormente divulgados. Todavia, a determinação deste marco não é unanimidade entre pesquisadores e profissionais da área. O ano de 1929 também é apontado quando se trata do início das ações de extensão rural. Neste ano foi realizada, na Escola Superior de Agricultura de Viçosa, a primeira Semana do Fazendeiro. Além destas datas, os anos de 1940 são citados no texto base da Política Nacional de Assistência Técnica e Extensão Rural - PNATER como referência temporal. Na já referida década de 1940, as ações de ATER estavam voltadas à melhoria da qualidade de vida e modernização da agricultura, conforme aponta o texto da PNATER:

Os serviços de Assistência Técnica e Extensão Rural - Ater, foram iniciados, no país, no final da década de quarenta, no contexto da política desenvolvimentista do pós-guerra, com o objetivo de promover a melhoria das condições de vida da população rural e apoiar o processo de 
modernização da agricultura, inserindo-se nas estratégias voltadas à política de industrialização do país. A Ater foi implantada como um serviço privado ou paraestatal, com o apoio de entidades públicas e privadas. Posteriormente, com apoio do governo do presidente Juscelino Kubitschek, foi criada, em 1956, a Associação Brasileira de Crédito e Assistência Rural - ABCAR, constituindo-se, então, um Sistema Nacional articulado com Associações de Crédito e Assistência Rural nos estados. Em meados da década 1970, o governo do presidente Ernesto Geisel "estatizou" o serviço, implantando o Sistema Brasileiro de Assistência Técnica e Extensão Rural - Sibrater, coordenado pela Embrater e executado pelas empresas estaduais de Ater nos estados, as Emater (BRASIL, 2004, p. 04).

O período de 1950-1970 é marcado pela utilização de novas tecnologias, especialmente a mecanização e insumos químico-industriais, maximização das áreas de plantio e produção de commodities. Este processo de modernização agrícola propiciou o aumento de mão de obra disponível, principalmente no espaço urbano, concomitantemente ao que a produção agrícola voltouse a exportação e industrialização. O modelo de ATER praticado neste período vai ao encontro deste pacote "tecnológico",

[...] a Extensão Rural com o apoio norteamericano aos países do terceiro mundo começa a vigorar no Brasil. O discurso de capacitar as famílias e comunidades pobres e dar condições necessárias para se capitalizarem fracassou, uma vez que eles não dispunham de capital para adquirir os equipamentos agrícolas necessários para tal evolução. Assim, após algumas reuniões entre os extensionistas, que colocavam em prática o plano de extensão rural, resolveram mudar sua estratégia e trabalhar com os agricultores que dispunham de capital para fazer a aquisição desses (Redin \& Fialho, 2010, p. 04).

Esta situação começa a sofrer críticas em fins da década de 1970. Simultaneamente, os modelos ambientalistas e de agricultura alternativa passam a emergir. Temas como reforma agrária, agroecologia e missão do serviço público passam a ser discutidos quando o término da ditadura militar e início da Nova República brasileira (Peixoto, 2008). Tais temas começam a vigorar na ordem do dia, sendo desenvolvidas ações para os agricultores e assentados rurais no $1^{\circ}$ Programa Nacional de Reforma Agrária (PNRA), Decreto n 91.766, de 10 de outubro de 1985.

O advento da Constituição de 1988 trouxe contribuições para a política agrícola brasileira:

Art. 187. A política agrícola será planejada e executada na forma da lei, com a participação efetiva do setor de produção, envolvendo produtores e trabalhadores rurais, bem como dos setores de comercialização, de armazenamento e de transportes, levando em conta, especialmente:

I - os instrumentos creditícios e fiscais;

II - os preços compatíveis com os custos de produção e a garantia de comercialização;
III - o incentivo à pesquisa e à tecnologia;

IV - a assistência técnica e extensão rural;

$\mathrm{V}$ - o seguro agrícola;

VI - o cooperativismo;

VII - a eletrificação rural e irrigação;

VIII - a habitação para o trabalhador rural.

$\S 1^{\circ}$ Incluem-se no planejamento agrícola as atividades agroindustriais, agropecuárias, pesqueiras e florestais.

$\S 2^{\circ}$ Serão compatibilizadas as ações de política agrícola e de reforma agrária (Brasil, 1988).

Apesar da assistência técnica e extensão rural serem indicada no texto Constitucional, a Lei 8.171, que dispõe sobre a política agrícola é, somente em 17 de janeiro de 1991, sancionada. No interstício supracitado há que ser salientado o fato de, durante o governo do presidente Fernando Collor, em 1990, o SIBRATER ser definitivamente extinguido. As ações de ATER são severamente atingidas.

A reiteração da ATER como integrante da política agrícola aponta para a necessidade de ações integradas, que garantam à população rural o direito ao assessoramento - não apenas no que diz respeito a produção - mas também a qualidade de vida da população.

Diante deste cenário, alguns estados e municípios lançam mão de iniciativas de ATER, passando a apoiar organizações não-governamentais e instituições sem fins lucrativos. Entretanto, tais ações não foram suficientes, uma vez que a demanda aumentou proporcionalmente a diminuição dos recursos. A escassez de ações de ATER ocasionou o agravamento das desigualdades, visto que a falta de informações, a dificuldade para acessar políticas públicas, entre outros aspectos dificultaram o pleno desenvolvimento socioeconômico. Apenas no ano de 2003, no governo de Luís Inácio Lula da Silva, a ATER retorna a pauta.

Em 2004, a ATER passa a ser pautada pela Política Nacional de Assistência Técnica e Extensão Rural (PNATER). Em uma perspectiva agroecológica a PNATER propõe processos democráticos e participativos, sublinhando que:

[...] a Ater, como um dos instrumentos de apoio ao desenvolvimento rural, adote uma missão, objetivos, estratégias, metodologias e práticas compatíveis com os requisitos deste novo processo. Para dar conta destes desafios, os serviços públicos de Ater (realizados por entidades estatais e não estatais) devem ser executados mediante o uso de metodologias participativas, devendo seus agentes desempenhar um papel educativo, atuando como animadores e facilitadores de processos de desenvolvimento rural sustentável. Ao mesmo tempo, as ações de Ater devem privilegiar o potencial endógeno das comunidades e territórios, resgatar e interagir com os conhecimentos dos agricultores familiares e demais povos que vivem e trabalham no campo em regime de economia familiar, e estimular o uso sustentável dos recursos locais (Brasil, 2004).

A Lei 12.188 de 11 de janeiro de 2010, a qual institui a Política Nacional de Assistência Técnica e Extensão Rural para a Agricultura Familiar e Reforma Agrária - 
PNATER e o Programa Nacional de Assistência Técnica e Extensão Rural na Agricultura Familiar e na Reforma Agrária - PRONATER, determina categoricamente a ATER no Brasil como sendo um "(...) serviço de educação não formal, de caráter continuado, no meio rural, que promove processos de gestão, produção, beneficiamento e comercialização das atividades e dos serviços agropecuários e não agropecuários, inclusive das atividades agroextrativistas, florestais e artesanais" (Brasil, 2010). Chama atenção que a metodologia de trabalho defendida pela nova PNATER pressupõe processos de educação não formal, dialógicos, participativos. A extensão, vista como resultado da construção coletiva do conhecimento, diferencia-se daquela praticada no passado que impunha pacotes tecnológicos. A extensão baseada nesta metodologia valoriza o saber, promove a educação. Conforme Paulo Freire "a educação é comunicação, é diálogo, na medida em que não é a transferência de saber, mas um encontro de sujeitos interlocutores que buscam a significação de significados" (Freire, 1985, p. 46).

Inaugura-se um direcionamento no qual a ATER tem importância para a redução das desigualdades, preocupando-se não somente com a produção agrícola, mas também com as condições e qualidade de vida da população rural e o pleno exercício da cidadania.

\section{A EMATER}

A EMATER/RS - ASCAR presta assistência técnica e extensão rural no Rio Grande do Sul desde 1955. Com doze escritórios regionais distribuídos pelo estado, a EMATER/RS - ASCAR se faz presente no cotidiano de diversas famílias de agricultores.

De acordo com Teixeira (2008) inicialmente, o objetivo da EMATER/RS era desenvolver a agricultura e o bemestar das populações rurais por meio do crédito supervisionado e da assistência. A atuação desta instituição passa por alterações com a implantação da ABCAR e posteriormente da EMBRATER, devendo ter suas ações norteadas por princípios e diretrizes federais. Diante às imposições administrativas e legais determinadas pelos governos militares brasileiros, os estados criam suas instituições próprias de ATER, surgindo as EMATERs. No Rio Grande do Sul, a EMATER/RS (Associação de Empreendimentos de Assistência Técnica e Extensão Rural) foi criada constituindo-se numa entidade civil, sem fins-lucrativos e de direito privado (Teixeira, 2008).

A abrangência territorial da EMATER/RS, segundo dados disponíveis no site da instituição são superiores a 480 municípios, equivalendo a mais de 250 mil famílias (Figura 1). No tocante ao número de funcionários, o site institucional da EMATER/RS informa que estes perfazem um total de mais de 2 mil trabalhadores. Sobre as ações implementadas pela organização destacam-se:

[...] orientar o uso de tecnologias nas mais diversas áreas, quer na área de saneamento básico ou ambiental, quer para melhorar o desempenho de lavouras. Porta-voz da integração do jovem no meio rural e agente transformador da informação, repassa conhecimentos e experiências por meio de mais de oito eventos diários que promove diariamente na geografia gaúcha ou através de programas em rádios e tevês e publicações (EMATER, 2016).

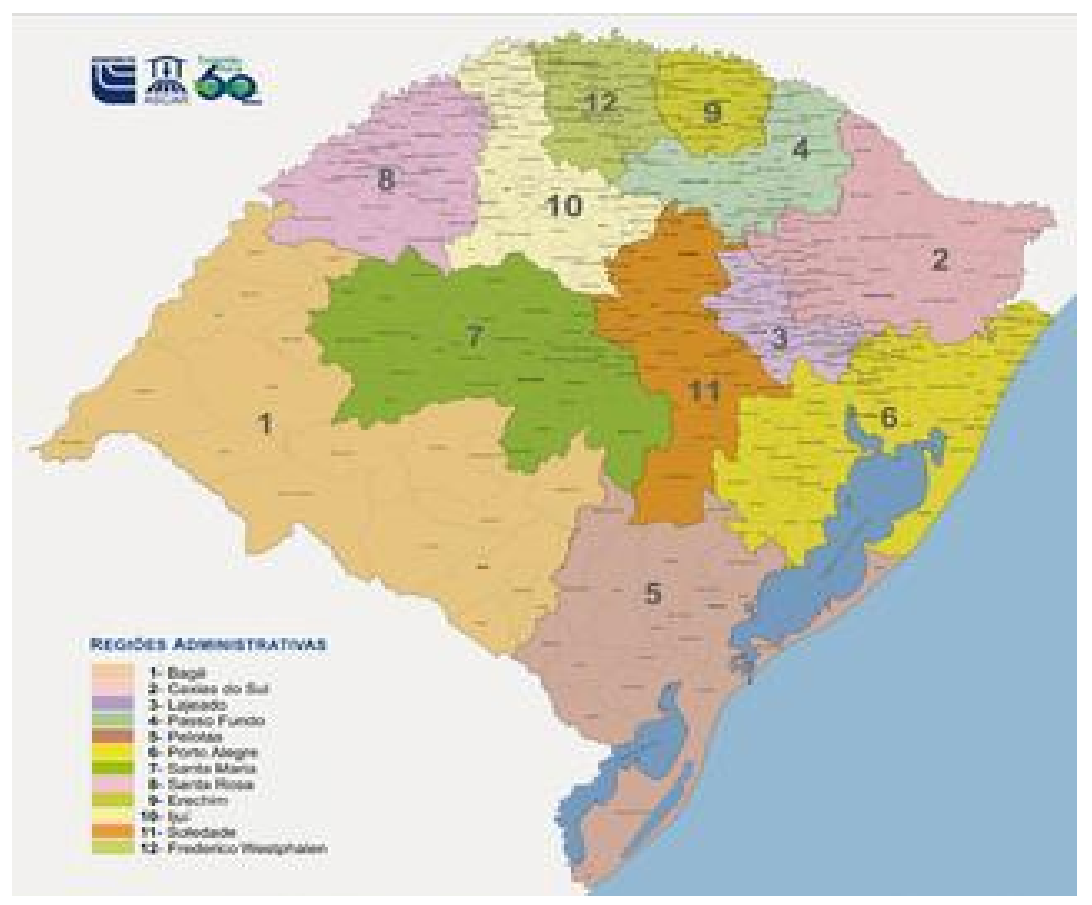

Figura 1. Mapa do estado do Rio Grande do Sul/Br com referência as regiões administrativas da EMATER/RS. FONTE: Rio Grande Rural. 
Nota-se que o texto institucional diverge de alguns pressupostos defendidos pela PNATER, essencialmente, o qual versa sobre participação e construção do conhecimento a partir de experiências endógenas as comunidades. O mesmo pode-se dizer com relação ao excerto a seguir:

[...] A agenda diária coloca em prática um conjunto de ações educativas e concretas que resultam no abastecimento de água para consumo humano, na disposição adequada dos esgotos domésticos e dos resíduos sólidos das propriedades rurais, e iniciativas que asseguram a segurança alimentar dos públicos assistidos, entendida principalmente como a produção de alimentos na propriedade (EMATER, 2016).

As ações de extensão previstas na PNATER operam para além de questões de ordem prática, como, por exemplo, o abastecimento de água para o consumo humano. Trata-se de atividades que buscam o desenvolvimento rural sustentável, em que as esferas social, econômica, produtiva, histórica, etc. estejam contempladas. Neste horizonte, há igualmente uma preocupação com os resultados de médio e longo prazo, dentre os quais a preservação ambiental, a sustentabilidade das atividades agrícolas e a reprodução social sejam asseguradas.

\section{O SERVIÇO SOCIAL E A EXTENSÃO RURAL NO BRASIL: UMA ANÁLISE A PARTIR DA TEORIA BOURDIESIANA}

Entende-se que as ações de extensão não estão deslocadas espacial e temporalmente, pelo contrário, ocorrem em contextos diversos. Assim, analisar as relações existentes entre os diversos atores é de suma relevância para compreensão dos processos e situações identificados. Para tanto, optou-se por utilizar a teoria bourdiesiana, ou seja, conceitos como campo, capital e relações de poder foram examinadas a partir deste viés.

As ações de extensão rural voltadas à área social costumeiramente foram relegadas a categoria secundária, de menor importância. $\mathrm{O}$ foco do trabalho com ATER esteve por um longo período associado a noções de produção agrícola com ênfase na produtividade. Assim, predominavam as figuras do engenheiro agrônomo e do técnico agrícola como protagonistas da ATER. O envolvimento de outros profissionais, especialmente daqueles considerados da área social, foi gradativo. O espaço conquistado por esses profissionais, dentre eles os assistentes sociais, tem sido parte integrante de um processo que observa aspectos mais complexos do desenvolvimento rural.

Ao considerar diversos aspectos, o conceito de desenvolvimento rural combina, "o aspecto econômico (aumento do nível e estabilidade da renda familiar) e o aspecto social (obtenção de um nível de vida socialmente aceitável), e que sua trajetória principal possa residir na diversificação das atividades que geram renda (pluriatividade)" (Kageyama, 2004, p. 10). Logo, o desenvolvimento rural sopesa diferentes variáveis. Requer antes a necessidade de promover não apenas a renda e/ou a questão econômica das famílias. Nesse sentido, a participação de profissionais de diferentes áreas na extensão rural possibilita um trabalho mais abrangente e coerente com estes preceitos.

Refere-se então a valorização da construção coletiva do conhecimento, sendo este construído na relação entre os profissionais de ATER e destes para com o público a que se direcionam as ações. É nesta interlocução que a extensão rural está alicerçada. O trabalho com ATER requer para além do conhecimento técnico a capacidade de ao observar e analisar como estão estruturadas, organizadas as relações sociais. Tal reconhecimento é importante, visto que o grau de inserção e/ou aceitação do agente de ATER e de suas orientações está diretamente relacionado à como esta relação se organiza. Desvela-se como se dão as relações de poder e, em que medida estas contribuem - ou não - para o êxito das ações propostas. Isto requer 0 conhecimento teórico-metodológico que permita intervir na realidade de maneira não impositiva, mas sim em conjunto com a população a quem se volta o trabalho. É uma relação construtivista, na qual não se despreza o fato de ser uma relação de poder.

[...] não basta notar que as relações de comunicação são, de modo inseparável, sempre, relações de poder que dependem, na forma e no conteúdo, do poder material ou simbólico acumulado pelos agentes (ou instituições) envolvidos nessas relações e que, como dom ou potlatch, podem permitir acumular poder simbólico. É enquanto instrumentos estruturados e estruturantes de comunicação e de conhecimento que os "sistemas simbólicos" cumprem a sua função política de instrumentos de imposição ou de legitimação da dominação [...] (Bourdieu, 2000, p. 11; itálico e aspas no original).

Essas relações de poder ao não serem ignoradas facilitam a compreensão de como os agentes atuam no campo. O poder está proporcionalmente relacionado ao capital, ou seja, quanto maior o capital, maior o poder que o indivíduo exerce sobre a realidade.

$\mathrm{Na}$ luta pela imposição da visão legítima do mundo social, em que a própria ciência está inevitavelmente envolvida, os agentes detêm um poder à proporção do seu capital, quer dizer, em proporção ao reconhecimento que recebem de um grupo. A autoridade que fundamenta a eficácia performativa do discurso sobre o mundo social, a força simbólica das visões e das previsões que têm em vista impor princípios de visão e de divisão desse mundo, é um percipi, um ser reconhecido e reconhecido (nobilis), que permite impor um percipere. Os mais visíveis do ponto de vista das categorias de percepção em vigor são os que estão mais bem colocados para mudar a visão mudando as categorias de percepção (Bourdieu, 2000, p. 145. Destacado no original).

Este poder perpassa as diversas conformações das relações sociais e influencia na maneira como as propostas de ATER transitam no campo. Isto é, uma proposta de trabalho ainda que não resultante da construção coletiva pode ser legitimada, dependendo do agente que a sugere. O risco está alocado justamente nesta legitimação, na medida que objetivos 
considerados imprescindíveis pelos agentes de ATER podem não ser os mesmos observados pelo públicoalvo. Ocorre ai um equívoco comum no que concerne a extensão, a falta de "escuta". Outrossim, a relação entre os profissionais de ATER é também uma relação de poder na medida em que os capitais operados diferem-se conforme a área de formação, cargo ocupado, reconhecimento, etc.

Acerca destes capitais, Pierre Bourdieu lança mão do conceito de capital cultural, o qual "[...] pode configurarse, segundo a teoria bourdiesiana, sob três formas: sob a forma de disposições duráveis do organismo, em estado incorporado; sob a forma de bens culturais, estado objetivado; e através do reconhecimento de títulos escolares, estado institucionalizado" (Radunz 2013, p. 34). O capital cultural institucionalizado é, na maioria das vezes, o acionado pelos agentes de ATER, dada a formação técnica (institucional) deste ator. A equação mais capital, mais poder é verdadeira. De mesmo modo, é preciso que o capital acionado seja aquele valorizado pelos sujeitos para aquela situação específica. O capital acionado pelos assistentes sociais e demais agentes de ATER é, em geral o capital cultural institucionalizado, uma vez que esses profissionais atuam no campo em decorrência da função exercida. Todavia, outros capitais podem ser movidos.

Ao discorrer sobre os demais conceitos que subsidiam este artigo, aponta-se que o trabalho social realizado em ATER volta-se para demandas que extrapolam solicitações pontuais e o atendimento da população pauperizada,

[...] abrange a dimensão produtiva e econômica, não só na preocupação com os resultados físicos ou financeiros, ou no entendimento do porquê se adota ou não uma certa tecnologia; mas na forma como se organiza essa produção, nas relações de poder que estruturam a ação das pessoas, nas implicações que os processos de organização social trazem para as mudanças concretas na vida de todos (Siliprandi, 2002, p. 39).

Ao tratar o social como conceito mais abrangente, no qual se faz necessário uma análise mais vasta e crítica da realidade, os profissionais precisam de uma expertise que lhes é própria da formação profissional. Assim, o assistente social, como profissional integrante da equipe multiprofissional de ATER, atua nas expressões da questão social de forma a garantir o acesso aos direitos e o pleno exercício da cidadania. Este profissional atua nesta política como facilitador, preconizando o empoderamento, a autonomia dos sujeitos, garantia de direitos e a eliminação das desigualdades. Salienta-se, as diferentes participações do assistente social na construção participativa alvitrada na PNATER, como, por exemplo, a elaboração do Diagnóstico Rural Participativo (DRP):

Diagnóstico Rural Participativo (DRP) é um conjunto de técnicas e ferramentas que permite que as comunidades façam o seu próprio diagnóstico e a partir daí comecem a autogerenciar o seu planejamento e desenvolvimento. Desta maneira, os participantes poderão compartilhar experiências e analisar os seus conhecimentos, a fim de melhorar as suas habilidades de planejamento e ação [...] a ideia é que os próprios participantes analisem a sua situação e valorizem diferentes opções para melhorá-la (Brasil, 2010, p. 12).

Esta é uma das atividades descritas pela PNATER nas quais o assistente social pode contribuir. Outrossim, cabe ao assistente social - agente de ATER - elaborar e executar projetos, participar da implementação e avaliação de políticas públicas, promover o controle social, etc.

Nesta conjuntura, evidencia-se a importância dada a assistência social no Decreto 51.565 de 9 de julho de 2014, que Regulamenta a Política Estadual de Assistência Técnica e Extensão Rural e Social no Estado do Rio Grande do Sul - PEATERS -, o Programa Estadual de Assistência Técnica e Extensão Rural e Social do Rio Grande do Sul - PROATERS -, o Fundo Estadual de Assistência Técnica e Extensão Rural e Social - FUNDATERS -, o Conselho Estadual de Desenvolvimento Rural Sustentável - CEDRS. Mais do que a sigla "S", o decreto supramencionado orienta a elaboração e execução de ações sociais, dando o enfoque necessário para esta área que por um longo período foi relegado ao ostracismo nas ações de ATER. No Art. $3^{\circ}$, sobre os princípios da PEATERS, ressaltase:

[...] III - garantia do acesso de forma continuada, permanente e planejada aos usuários da política de assistência social rural; IV - adoção de metodologia participativa, com enfoque multidisciplinar, interdisciplinar e intercultural, buscando a construção da cidadania e a democratização da gestão da política publica; [...] VI - equidade nas relações de gênero, geração, raça e etnia; [...] VIII - combate a pobreza, redução das desigualdades locais e regionais mediante ações de inclusão social e produtiva; IX - controle social; e X - respeito a autonomia e promoção da cidadania (RIO GRANDE DO SUL, 2014, p. 2).

Observa-se que, na legislação de ATER gaúcha, a assistência social recebe ainda maior destacamento. Tal preocupação com a qualidade de vida dos atendidos e com a assistência social está exposta nos objetivos - Art. $6^{\circ}$ - da ATERS gaúcha apontadas a seguir.

[...] II - promover a garantia ao acesso aos direitos e a oferta de serviços socioassistenciais; III - promover o desenvolvimento rural sustentável; [...] VI promover a melhoria da qualidade de vida de seus(suas) beneficiários(as); [...] XV -contribuir para a expansão do aprendizado, da educação e da qualificação profissional, de forma diversificada, apropriada e contextualizada a realidade do meio rural brasileiro; [...] XIX - reduzir as desigualdades sociais no meio rural com ações de combate a pobreza; XX - proporcionar condições para a melhoria da qualidade de vida da população rural com ações socioassistenciais na área da saúde, saneamento básico, habitação, educação, cultura e lazer; [...] XXII - capacitar usuários(as) dos serviços de assistência social rural para oportunizar a geração de trabalho e 
renda as famílias rurais; [...] (RIO GRANDE DO SUL, 2014, p. 3-4).

Não obstante, os objetivos da ATERS não sejam exclusivos de atuação do assistente social, a presença deste profissional nas equipes multidisciplinares possibilita um olhar mais crítico, haja vista que o objeto de trabalho deste é as expressões da questão social. Esta afirmação vem, ao longo deste trabalho sendo asseverada, uma vez que se encontra na realidade uma situação diferente da preconizada na legislação vigente e defendida pelas vertentes teóricas supracitadas.

A participação de profissionais na área social da EMATER/RS mantém-se aquém do considerado necessário para atender as demandas do público atendido na ATER no estado. Siliprandi (2002) ao discorrer sobre o percentual de trabalhadores alocados na EMATER/RS apontara:

São cerca de 2.300 empregados, sendo cerca de $25 \%$ com formação superior em Ciências Agrárias (engenheiros agrônomos, engenheiros florestais, médicos veterinários, zootecnistas) e $25 \%$ com formação de nível médio nesta área (técnicos agrícolas). No que se refere à área social, há uma desproporção: as extensionistas de bem-estar social (cargo de nível médio na empresa) correspondem a aproximadamente $18 \%$ do total de empregados, enquanto os profissionais com formação superior nessa área e contratados como tal (sociologia, antropologia, economia, pedagogia, serviço social, saúde, nutrição, saneamento) são cerca de $2 \%$ do total (Siliprandi, 2002, p. 41).

Atenta-se que, de acordo com os dados do site da EMATER/RS, atualmente constam no quadro mais de dois mil funcionários, porém em 2015 foram demitidos mais de duzentos funcionários. O percentual de funcionários lotados na área social permanece extremamente desigual se comparado à área técnica. Para atender a todo estado do Rio Grande do Sul foram contratadas apenas duas assistentes sociais. Estas são as únicas profissionais contratadas para desenvolver a função de assistente social, conquanto existem outras profissionais com esta formação, mas não exercendo tal função. Diante dos mais de quatrocentos municípios atendidos pela EMATER/RS, contar com apenas duas assistentes sociais evidencia um contrassenso no que diz respeito à dimensão social e ao desenvolvimento de ações vinculadas a assistência social.

O Serviço Social, enquanto profissão que surge no seio do capitalismo, com o acirramento das expressões da questão social, manifestadas especialmente no espaço urbano, no momento da industrialização e urbanização do país, historicamente dedicou seus olhares e sua intervenção para as cidades. Residualmente a profissão direciona-se para o rural, servindo como exemplo os trabalhos com Desenvolvimento de Comunidades (DC), que dedicaram particular atenção para as comunidades rurais durante a fase inicial do desenvolvimento desta metodologia (entre 1955 e 1965). Como consequência desta relação histórica entre o Serviço Social e o espaço rural, esta profissão tornou-se um tanto quanto desconhecida naquele lugar, seja com os técnicos que lá trabalham, seja com a população que lá vive e também trabalha (Lusa, 2013, p. 133).

De acordo com a assistente social entrevistada, as ações sociais da EMATER/RS são organizadas a partir de um Núcleo de Desenvolvimento Social, responsável por organizar as diretrizes da área social em âmbito estadual. Pautadas em programas e projetos essas, ações buscam atender quilombolas, indígenas, agricultores familiares, mulheres, jovens, idosos, etc.. Situações de sucessão e envelhecimento do público rural são igualmente sistematizadas neste núcleo. Ainda que escasso o número de trabalhadores na área social, percebe-se na fala da entrevistada, um esforço destes profissionais para atender as demandas oriundas da população rural, principalmente daqueles em situação de vulnerabilidade e/ou risco social, e participar das demais instâncias de discussão e planejamento das ações de assistência social.

A EMATER possui CEBAS (Certificado de Entidade Beneficente de Assistência Social) e, para tanto, há necessidade de manter o serviço social ativo. Contudo, pode-se notar - com base na pesquisa empírica e bibliográfica - que as ações voltadas a geração de renda, produção e produtividade estão postas como prioritárias. Ao dissertar sobre como estão organizadas as ações da EMATER/RS, a entrevistada mencionou a existência de um reordenamento das ações, no qual a área social está obtendo destaque. Este movimento pode ser, em parte, atribuído a exigência legal para manutenção do CEBAS. Apesar da presença do assistente social ser reconhecida, pelos demais extensionistas e pelo público atendido, não há valorização por parte do governo estadual. Exemplo disto a última seleção pública realizada em 2014, na qual foram aprovadas nove assistentes sociais e nenhuma fora nomeada. Todavia, houve diversas nomeações de profissionais de ensino médio para o cargo de técnico social. Tal situação demonstra que, os atores sociais responsáveis pelas instâncias de contratação de pessoal e composição das equipes multiprofissionais não compreendem a importância e necessidade de assistentes sociais no quadro da EMATER/RS.

Ainda sobre as ações promovidas pela EMATER/RS, a entrevistada relata que, embora existam diretrizes que norteiam o trabalho, é comum que o agente de ATER necessite atender das demandas de cada localidade. Ou seja, a urgência de algumas demandas imperam de tal maneira que acabam relegando a um segundo momento a elaboração dos diagnósticos. Ao ser questionada sobre as principais expressões da questão social, em âmbito estadual, a entrevistada aponta a falta de políticas públicas que atendam as especificidades do meio rural. A respeito disto, reportase o Programa de Combate à Pobreza no Meio Rural, gestado pelo governo federal, que destinou recursos de dois mil e quatrocentos reais por família em situação de vulnerabilidade. Com esta quantia foram, por exemplo, realizadas ações voltadas à segurança alimentar e nutricional, as quais geraram, conforme a entrevistada, excelentes resultados. $\mathrm{Na}$ opinião desta agente de ATER este tipo de programa também deveria ser proposto pelo Estado. 
A presença de um profissional do Serviço Social contribui, conforme analisado neste trabalho, de modo significativo para distinção entre assistencialismo e assistência social, tendo em vista que esta última caracteriza-se como política pública. Não obstante, esta temática também é pouco debatida nos espaços de formação profissional.

Enquanto agente promotor de saberes e práticas profissionais, cabe à academia promover a interlocução necessária entre os profissionais em exercício nesta política, o público usuário da mesma, a sociedade e a academia - que também é geradora de novos profissionais -, a fim de discutir profundamente as indagações que surgem da própria execução da política (Lusa, 2013, p. 133).

Indubitavelmente, o Serviço Social no meio rural e, por conseguinte as especificidades deste espaço são pouco debatidas durante na academia. $O$ assistente social como agente de ATER, em decorrência desta lacuna em sua formação e, em alguns casos, também por sua experiência pessoal, necessita buscar o conhecimento enquanto desenvolve sua função. Este hiato entre a formação e a prática profissional requer um olhar atento da academia, o qual buscou-se, junto as demais questões abordadas, instigar neste artigo.

\section{CONSIDERAÇÕES FINAIS}

A guisa de discutir o trabalho do assistente social como agente de ATER neste artigo lançou-se mão de pesquisa bibliográfica e empírica. Longe de encerrar o debate acerca da atuação do assistente social no meio rural, buscou-se instigar 0 leitor sobre as potencialidades e limites do exercício profissional neste campo. Neste mesmo horizonte, verificou-se que esta temática carece de um debate mais amplo. Ao passo que, tem-se notado que o trabalho do assistente social no meio rural tem ganho maior destaque $e$ reconhecimento. Sem embargo, há que se considerar o meio rural e as particularidades deste campo como objetos de trabalho do Serviço Social, tanto como o meio urbano.

Pretendia-se, ao término da pesquisa, compreender a dinâmica de trabalho do assistente social lotado na EMATER/RS. Acredita-se que diante do exposto anteriormente é possível - ainda que de maneira incipiente - atender a este objetivo. Verificou-se que o número de assistentes sociais vinculadas à EMATER/RS é insuficiente para atender a demanda. A instituição conta com apenas duas profissionais para atender a todo estado do Rio Grande do Sul. Igualmente, o número de profissionais vinculados a área social é ínfimo quando comparado ao da área técnica (leia-se agrônomos e técnicos agrícolas). Não bastasse a extensão territorial, foi possível ao longo deste trabalho, identificar que a demanda por ações de ATER voltadas a área social são inúmeras.

Nota-se que a importância do assistente social na equipe de ATER na EMATER/RS tem sido reconhecida pelo público atendido e demais agentes de ATER. No entanto, este reconhecimento ainda está em processo, ou seja, não alcançou o patamar esperado pela categoria profissional. Assistência e assistencialismo são, de acordo com apurado, confundidas pelas equipes, sendo estas esclarecidas pelas poucas profissionais do Serviço Social. Tal situação ambígua reflete, novamente a importância de contar com profissionais formados em Serviço Social, os quais possuem o conhecimento necessário para intervir. Então, confirma-se parcialmente a hipótese de que os profissionais de assistência social não tem seu papel e importância reconhecidos pelos gestores/governo estadual. Esta parcialidade ocorre em função do reconhecimento imputado pelo público atendido e alguns agentes de ATER às assistentes sociais da EMATER/RS.

Por fim, reitera-se que a temática ora abordada demanda novas pesquisas e o aprofundamento da discussão. Reconhecer o meio rural como espaço de atuação profissional postula compreender as particularidades deste campo e imergir em um campo ainda pouco abordado pela academia.

\section{REFERÊNCIAS}

Bourdieu, P. 2000. O poder simbólico. $3^{a}$ ed. Rio de Janeiro: Bertrand Brasil.

BRASIL. 2004. Política Nacional de Assistência Técnica e Extensão Rural. Brasília.

BRASIL. 1988. Constituição da República Federativa do Brasil. Brasília, DF: Senado Federal.

BRASIL. 2010. Lei 12.188, de 11 de janeiro de 2010. Dispõe sobre a instituição da Política Nacional de Assistência Técnica e Extensão Rural para a Agricultura Familiar e Reforma Agrária - PNATER e o Programa Nacional de Assistência Técnica e Extensão Rural na Agricultura Familiar e na Reforma Agrária PRONATER, altera a Lei no 8.666, de 21 de junho de 1993, e dá outras providências. Disponível em:

< http://www.planalto.gov.br/ccivil_03/_Ato20072010/2010/Lei/L12188.htm> acesso em agosto de 2017.

EMATER. 2016. Apresenta texto sobre a Apresentação Institucional. Disponível em: http://www.emater.tche.br/site/a-

emater/apresentacao.php\#.V1bh1fkrLDc. Acesso em 28 de maio de 2017.

EMATER. 2016. Rio Grande Rural - Mapa de abrangência das regionais. Disponível em: https://www.google.com.br/search?q=mapa+de+abrang $\%$ C3\%AAncia+emater+rs\&rlz=1C1AVNG_enBR702BR 706\&source $=$ Inms\&tbm=isch\&sa $=X \&$ ved $=0$ ahUKEwirpZ jw3PvaAhXCC5AKHWBzAXQQ_AUICygC\&biw=1366\& bih=672\#imgrc=5aCcATa0kyXdMM: Acesso em 09 de maio de 2018

Freire, P. 1985. Extensão ou Comunicação? 8.ed. Rio de Janeiro: Paz e Terra.

Kageyama, A. 2004. Desenvolvimento Rural: conceito e medida. Cadernos de Ciência \& Tecnologia. 21: 379408.

Lusa, M.G. 2013. Política Nacional de Assistência Técnica e Extensão Rural e Serviço Social: O campo como desafio. Cadernos Ceru. 24: 115-153.

Peixoto, M. 2008. Extensão Rural no Brasil - uma abordagem histórica da legislação. 50 p. Consultoria Legislativa do Senado Federal. Centro de estudos. Texto 48. 
Radunz, A.F.O. 2013. Agricultura familiar, relações de poder e mercados institucionais: Estudo de caso sobre o Programa Nacional de Alimentação Escolar no município de São Lourenço do Sul. 134f. Dissertação (Mestrado em Ciências Sociais) -Coordenação de PósGraduação em Ciências Sociais da Universidade Federal de Pelotas, Pelotas.

Redin, E. \& Fialho, M.A.V. 2010. Política agrícola brasileira: uma análise histórica da Inserção da agricultura familiar. In: Sociedade Brasileira de Economia, Administração e Sociologia Rural, p.1-19.

RIO GRANDE DO SUL. Decreto n. 51.565, de 9 de junho de 2014. Regulamenta a Política Estadual de Assistência Técnica e Extensão Rural e Social no Estado do Rio Grande do Sul - PEATERS -, o Programa Estadual de Assistência Técnica e Extensão Rural e Social do Rio Grande do Sul - PROATERS -, o Fundo Estadual de Assistência Técnica e Extensão Rural e Social - FUNDATERS -, o Conselho Estadual de Desenvolvimento Rural Sustentável - CEDRS. Porto Alegre, 2014, p.1-17.

Santos, R.A. 2010. Assistência técnica e extensão rural espaço sócio-ocupacional, para os assistentes sociais. Anais do $3^{\circ}$ Salão de Extensão e Cultura da UNICENTRO. Disponível em http://anais.unicentro.br/sec/iiisec/pdf/trabalho_19.pdf.

Acesso em 01 de Junho de 2017.

Siliprandi, E. 2002. Desafios para extensão rural: o "social" na transição agroecológica. Agroecologia e Desenvolvimento Rural Sustentável. 3: 38-48.

Silva, E.A. da. 2017. Atuação do assistente social nas ações de assistência técnica e extensão rural: elementos para reflexão. Anais do I Colóquio Internacional IV Colóquio Nacional sobre o Trabalho do/a Assistente Social. Disponível em file://C:/Users/Asus/Downloads/3692-13168-1-SM.pdf Acesso em 05 de maio de 2018.

Teixeira, E.M.R. 2008. A educação ambiental na extensão rural: uma análise a partir das concepções e práticas dos extensionistas rurais da EMATER/RSASCAR da região de Estrela - RS. 234f. Dissertação (Mestrado em Ambiente e Desenvolvimento) Coordenação de Pós-Graduação em ambiente e Desenvolvimento do Centro Universitário UNIVATES, Lageado. 